\title{
La imaginación como fuente de la historia política ${ }^{\mathrm{A}}$
}

\section{Germán Colmenares}

En un sugestivo artículo ("La política como fuente de la historia", en Lecturas Dominicales de El Tiempo, $1^{\circ}$ de febrero de 1987) María Carrizosa de López vuelve por los fueros de la historia política, "descalificada" a sus ojos por todas las vertientes de la "Nueva historia". Propone, de acuerdo con Jacques Julliard, redefinir el objeto de una posible historia política descartando la narrativa, anecdótica tradicional. Este nuevo objeto, capaz de afirmar de nuevo la autonomía de lo político sobre estructuras económicas y sociales, debe concentrar su análisis en los fenómenos del poder.

Este artículo de María Carrizosa expresa una inquietud que puede atribuirse a un círculo creciente de nuevos historiadores en Colombia. Esta inquietud sobre cómo es posible retomar la historia política sin incurrir en una narrativa factual y sin imaginación parece muy pertinente en vista del alud de trabajos anodinos con que periódicamente nos dejan sepultados los centenarios. Las efemérides son en Colombia la ocasión de trabajos generosamente financiados pero cuyos alcances están limitados por la premura de amontonar hechos y por las expectativas publicitarias de un gobierno o de una institución. Pero vale la pena examinar de cerca los términos en que está formulada la invitación de la historiadora, que sugieren algunas reflexiones sobre los problemas de la historia política en Colombia.

En primer término, ella se inclina a atribuir la "descalificación" de la historia política sobre todo al marxismo, el cual habría orientado las investigaciones hacia la historia económica y social. Esta es una curiosa versión si se tiene en cuenta el debate que a comienzos del siglo entablaron en Francia los sociólogos positivistas contra la historia factual, la "historia historizante" o la "historia-batalla", o si se tiene en

A Para esta transcripción disponemos de una copia en máquina -5 páginas—, que reproducimos íntegramente, aunque con el agregado de algunas comas y completando algunas comillas que el autor olvidó cerrar. En la parte superior izquierda se lee "10 de febrero de 1987”, pero nada se dice sobre el lugar de publicación, en caso de que el texto hubiera sido publicado - la fecha corresponde a una semana después de la publicación del texto al que Colmenares se refiere-. No conocemos casi nada sobre el contexto de esta discusión. En el plano historiográfico internacional se puede señalar la reivindicación de la política, como columna vertebral del análisis social, que había hecho Jacques Le Goff, en contra de lo que denunciaba como el "economicismo" de la historia económica y social —aunque la autora cita es a Jacques Julliard—, la nueva complejidad del análisis político sobre todo a partir de su vinculación con la antropología, y la recuperación de la herencia analítica del Marc Bloch de Los reyes taumaturgos. En el contexto nacional una discusión, más anunciada que realizada, entre ciencia política e historia política, con énfasis en sus métodos y en sus dimensiones temporales, y la aparición de formas de análisis político vinculadas a la investigación de las formas y relaciones sociales - es decir vinculadas a la historia social-, como las que trataron de poner en marcha algunos de los renovadores de la historia de la violencia en Colombia en esos años. De doña María Carrizosa de López, la autora del texto del que se ocupa Colmenares, hay varias huellas bibliográficas en el catálogo de la Biblioteca Luis Ángel Arango. 
cuenta que estos debates fundaron la prestigiosa Escuela de Annales. Desde el lado marxista, nada invita más a una historia política repleta de matices que los estudios [por ejemplo] de Christopher Hill sobre la Revolución Inglesa. En el caso colombiano el periodo de la Guerra de los Mil Días ha sido estudiado por Charles Bergquist con análisis que se mueven de la coyuntura económica a las circunstancias sociales y de allí a los eventos políticos. No hay ninguna otra guerra civil colombiana, ni siquiera las de la Independencia, sobre la que tengamos una imagen tan lúcida. Otra tanto podría decirse de los estudios de Gonzalo Sánchez y de Carlos Miguel Ortiz Sarmiento sobre la violencia.

Podría agregarse que no se trata, como lo sugiere María Carrizosa, de introducir análisis estructurales que nos devuelvan a la certeza de estar trabajando sobre la "larga duración", como si regresáramos a una tierra prometida, sino de lograr una comprensión real de los fenómenos políticos en una variante tal vez única, la colombiana. Un trabajo ejemplar sobre la historia económica del siglo XIX, como el de José Antonio Ocampo, no está invitando a fundar sobre él un determinismo en la interpretación política, sino que resulta imprescindible para señalar los límites necesarios dentro de los cuales debían moverse muchas opciones políticas.

En segundo lugar, la autora cree que, en el caso colombiano, la historia política debe recobrar un primado que ha sido oscurecido por la historia económica y social. Ella nos dice: "Es de tener en cuenta que en el proceso colombiano en donde las estructuras económicas y sociales no tienen el mismo arraigo que en sociedades más autónomas en donde cada etapa ha sido el proceso de evoluciones más naturales, aumenta la capacidad de todo lo concerniente a la estructura política en cuanto a controlar la totalidad de las relaciones sociales". Este es un pasaje un poco alusivo pero la elipsis recela una hipótesis central en su razonamiento. Por eso vale la pena intentar un esfuerzo de traducción. Veamos: 1. Las estructuras sociales y económicas en Colombia son inestables (no están arraigadas), vale decir, ni siquiera se trata de estructuras; 2. Hay sociedades más autónomas, es decir que, por implicación, la sociedad colombiana es menos autónoma. Algunos prefieren decir abiertamente: dependiente. En esas sociedades más autónomas ha habido etapas (¿modos de producción? ¿etapas de progreso lineal?) cuya evolución ha sido más natural que en Colombia. ¿Sería ir demasiado lejos en nuestro ejercicio de traducción aventurar que la autora quiere decir que esas sociedades sí tienen historias? 4. Ergo, en Colombia, debido a la inestabilidad de las estructuras económicas y sociales y a la artificialidad (por oposición a "natural") de las etapas de su desarrollo, debe asignarse a lo político, a la "acción consciente" (¿de quiénes?) un primado en el control de las relaciones sociales. En otras palabras, las cosas no han ocurrido aquí como en otras partes, las clases sociales tienen una existencia tan precaria que no vale la pena detenerse en ellas, el país es tan evanescente que lo único que queda como control (y por supuesto como inteligible) de las relaciones sociales es lo político. Bueno, no otra cosa nos ha dicho la historiografía 
tradicional. En ella lo político y solo lo político quiere aparecer como una síntesis de la manera de ser colectiva, de sus aspiraciones o de sus frustraciones.

Todo esto no quiere decir que no haya una urgencia de escribir una historia política. Pero no debe partirse del supuesto de que lo económico o lo social oscurecen un universo político autónomo. De acuerdo: esta "nueva-nueva" historia política debe estar centrada en el análisis de los fenómenos del poder. Pero no podía olvidarse que tales fenómenos desbordan una acción política encaminada exclusivamente al control de los aparatos centrales del Estado. Y no se trata solamente de considerar, como factores políticos, la enorme diversidad de grupos capaces de desatar conflictos en un momento histórico dado: "castas" todavía a comienzos del siglo XIX, tensiones entre el centro y las periferias regionales, la manera como se interiorizaron los conflictos partidistas en las regiones, desplazamientos masivos [de poblaciones ] hacia las vertientes y regiones bajas, tensiones entre movimientos colonizadores y regulaciones y privilegios obtenidos del poder central entre nubes de abogados y especuladores (en este punto el trabajo de Catherine Legrand debería dar un vuelco a todas nuestras interpretaciones políticas convencionales), cinturones urbanos de miseria en el siglo $\mathrm{XX}$ y procesos de negociación con los servicios públicos, etc. Dudo mucho que todo este caótico proceso haya sido siquiera entrevisto (¿para qué hablar de control?) por una estructura política dotada de alguna forma de conciencia.

No, ni siquiera se trata de eso, es decir, de comenzar la tarea de una historia social que está por escribirse casi íntegramente. Se trata de abordar lo político desde otros ángulos que le confieran una autonomía real y no simplemente la ilusión de una "acción consciente" de las clases políticas. Si de algo adoleció la historiografía política tradicional colombiana no fue solamente de ignorar las estructuras políticas y sociales. En sus interpretaciones había un divorcio todavía más profundo entre la política y la cultura. De la cultura entendida, claro está, como "un tejido de significados encarnados en símbolos y transmitidos históricamente, un sistema de concepciones heredadas expresadas de manera simbólica, por medio de las cuales los hombres se comunican y desarrollan su conocimiento sobre la vida y las actitudes hacia la vida" (Clifford Geertz).

Sería demasiado largo e impertinente clarificar por entero en qué consistía ese divorcio entre la política y la cultura. Baste observar por ahora que el poder está asociado con símbolos y ceremonias, de las cuales el historiador político debe desentrañar el significado. La rebelión misma se ciñe a patrones, a rituales, que revelan una cultura. Por lo demás, el análisis del lenguaje político no se agota en la formulación explícita de una ideología. Ciertas ceremonias colectivas (piénsese en el 9 de abril de 1948) hacen parte del lenguaje político. Además de su denotación explícita, este lenguaje posee connotaciones inscritas en el tejido de significados a que alude Geertz.

Por estas razones, la "nueva-nueva" historia política no deberá estar basada solamente en modelos prestados de la ciencia política (sobre las servidumbres de la 
ciencia debería pensarse dos veces), sino también en el análisis antropológico y en los modelos lingüísticos. Debemos convencernos de que ciertas convenciones del lenguaje político en América Latina son meras adaptaciones, torpes o sensatas, de convenciones europeas. Por esta razón los análisis formales de tipo jurídico o los análisis de contenido ideológico se mueven en el equívoco. ¿Estamos aludiendo con ellos a una realidad americana, o a una realidad europea? En muchos casos, lo que para los europeos es etnografía, para nosotros hace parte de nuestra propia historia.

Este reclamo por una historia política como "acción consciente" (¿de una minoría esclarecida?) esconde a veces la angustia frente a lo social caótico. Algo parecido escondía la dicotomía de Sarmiento entre civilización y barbarie. Pero sería inútil escondernos de una "cultura de la violencia" que permea todos los poros de nuestra sociedad, particularmente sus poros políticos. La tarea del historiador no consiste en defenderse de ominosas amenazas que pesan sobre su sociedad, sino de tratar de comprender una historia, toda la historia colombiana. Querámoslo o no, el divorcio entre política y cultura (en el sentido profundo que se ha señalado) definió toda la tarea historiográfica del siglo XIX y sus prolongaciones parasitarias del siglo XX. ¿Para qué insistir en mantener este fracaso como si se tratara de una tarea intelectual legítima? La tarea para los "nuevos-nuevos" historiadores es enormemente estimulante. Ella implica enfrentarse a la historia política enriquecidos con toda la panoplia de las ciencias sociales y con todos los instrumentos críticos al alcance de la mano. Pero, por favor, no regresemos a la hagiografía seglar o a una narrativa decimonónica de la que toda la imaginación interpretativa ha sido desterrada. 